\title{
A DUAL PORT SPATIALLY DIVERSE ANTENNA SYSTEM FOR COGNITIVE RADIO APPLICATIONS
}

\author{
Laith Wajeeh Abdullah ${ }^{1}$
}

\author{
${ }^{*}$ Qasim H. Kareem ${ }^{2}$ \\ Adheed Hasan Sallomi ${ }^{4}$
}

Malik Jasim Farhan ${ }^{3}$

1,2) Ph.D. Student، Electrical Engineering Department, Mustansiriyah University, Baghdad, Iraq

3) Asst. Prof., Electrical Engineering Department, Mustansiriyah University , Baghdad, Iraq

4) Prof., Electrical Engineering Department, Mustansiriyah University , Baghdad, Iraq

\begin{abstract}
This paper presents a dual-port antenna system that combines the features of both cognitive radio and MIMO diversity. The system is designed on a compact size $90 \times 70 \times 1.6 \mathrm{~mm}^{3} \mathrm{FR} 4$ substrate with PIN diodes integrated within feed line to achieve frequency reconfigurability. The proposed design can be switched between a Wide Band (WB) sensing mode (2.24-4.5 GHz) and four communication modes that serve WiMax, Wi-Fi and Cband applications. A single-band (3.2-3.72 GHz) and dualband $(2.28-2.46 \mathrm{GHz} / 3.85-4.2 \mathrm{GHz})$ with their MIMO duplicates are accessible in communication modes of operation. The proposed antenna system is designed using CST full-wave modeling under realistic electromagnetic effects and its feasibility as a cognitive radio system is verified by highly acceptable results regarding S-parameters, realized gain and impedance matching. System's reliability as a MIMO system is ensured by envelope correlation coefficient, diversity gain and mutual coupling fairly good results. All outcomes confirm that the proposed system looks promising as a MIMO cognitive radio system.
\end{abstract}

Keywords: Cognitive Radio, MIMO, Diversity, ECC

\section{Introduction}

Networks without cables play a tremendous role day after day in our life demands. Antennas are the basic tools for Billions of wireless devices to communicate. So, for our portable needs how to design those antennas to be as small and light as possible is one of the main targets of the designers. On the other hand limitations of frequency resources that is so related to the huge increase in wireless terminals and the wide variety of technologies used for wireless networking has forced the researchers in this field to find solutions that enables more efficient utilization of the available resources. Luckily, compact microstrip antennas when combined with the goals of cognitive radio and MIMO terminologies will be capable to serve most of today's and tomorrow's requirements.

Microstrip antennas with reconfiguration capabilities have been designed to fulfill the requirements of cognitive radio that has to operate under one of these modes: underlay where secondary users can access primary users spectrum at very low power or interweave in which the secondary users make use of gaps in the primary users spectrum [1]. The first mode is usually implemented by a single-port antenna whereas both single-port and dual-port antennas can be used for the second mode [2]. Reconfigurability is usually obtained by different 
switching techniques usually accompanied by various modifications in traditional shapes of microstrip patch antennas. Among the switching techniques, PIN diodes [3-6] are most commonly used in reconfigurable antennas. Other techniques depend varactor diodes [7], MEMS [8] and optical switches [9]. Defected Ground Structures (DGS), slots, slits and/or stubs are common modifications that can be used in the antenna for reconfiguration purposes. On the other hand MIMO antennas improve channel efficiency and at the same transmission power can provide higher data rates [10, 11]. Agile frequency MIMO antennas that merge the features of both of them are best suited for wireless networking and cognitive radio systems of the $4 \mathrm{G}$ and $5 \mathrm{G}$ networks [12].

In this paper, several frequency reconfigurable MIMO based antenna systems that can be used for cognitive radio applications are surveyed. In [12] a triple-port cognitive radio system is proposed where a monopole is used for sensing the WB (0.72-3.44 GHz) and two identical antennas are reconfigurable in the communication mode to be tuned in the bands (0.58-0.68 GHz) and (0834-1.12 GHz) via a pair of PIN and varactor diodes in each antenna. In [13]; two pairs of varactor diodes each bridging the two portions of rectangular antennas in dualport stacked antenna system are used for tuning the frequency within $(1.68-1.93 \mathrm{GHz})$ and (2.11$2.51 \mathrm{GHz}$ ) bands. [14] presents a two element MIMO system where each antenna is an agile frequency that has a varactor diode placed in a circular slot into the ground plane which enables tuning over the rang (2.12 -2.4 GHz). [15] and [16] both present a four element MIMO system symmetrical that depend slot based elements. A PIN diode in each of the circular slots or pentagonal slots are used to tune the system within (1.8-2.45 GHz) and (3.2-3.9 GHz) bands for [15] and [16] respectively but without wideband sensing capabilities. [17] presents a four element MIMO system that is reconfigurable in the band $(1.3-2.6 \mathrm{GHz})$ by a varactor diode in the feed-line and a modified rectangular patch with dual hexagonal-slot in the ground plane for each element. [18] presents a two element MIMO antenna for GSM, UMTS, and LTE applications which is integrated a metal rim structure suitable for use on smartphones.

In this article a dual-port antenna for interweave cognitive radio that makes use of MIMO is presented. The system which convolved two antennas on a $90 \times 70 \times 1.6 \mathrm{~mm}^{3}$ FR4 substrate of $\varepsilon \mathrm{r}=4.3$ and $\delta=0.0025$. The first antenna serves sensing/communication purposes for interweave cognitive radio. It is constructed as a three section antenna where the main section is a rectangular monopole modified by half elliptical hat and rectangular slot. It is used for perception of a WB within the range $(2.2-4.5 \mathrm{GHz})$. On the other hand, the two branch sections which are designed with different modifications in feedline, slots, and stubs are used for transmission into one of single-band and dual-band modes that targeting the WiMax and Wi-Fi/C-band applications respectively. All sections are designed with partial grounds. The second antenna which is a duplicate of the communication branches of the first antenna is used to achieve MIMO features. Enabling and disabling a certain section is done via PIN diodes. CST v.10 simulation results including reflection loss, realized gain, mutual coupling, radiation patterns and diversity gains and envelope correlation coefficient seem to be satisfactory to achieve the goals of the design. 


\section{Antenna system structure:}

The proposed antenna shown in Fig. 1 is built on a $90 \times 70 \mathrm{~mm}^{2}$ FR4 epoxy substrate having a thickness of $1.6 \mathrm{~mm}$ with a dielectric constant of 4.3 and a tangential loss of 0.0025 . The antenna system is a dual-port antenna where the first (Antenna-1) is a frequency reconfigurable sensing/communication antenna dedicated for cognitive radio applications while the second (Antenna-2) is an inverted copy of the communication sections of the first one that provides diversity features.

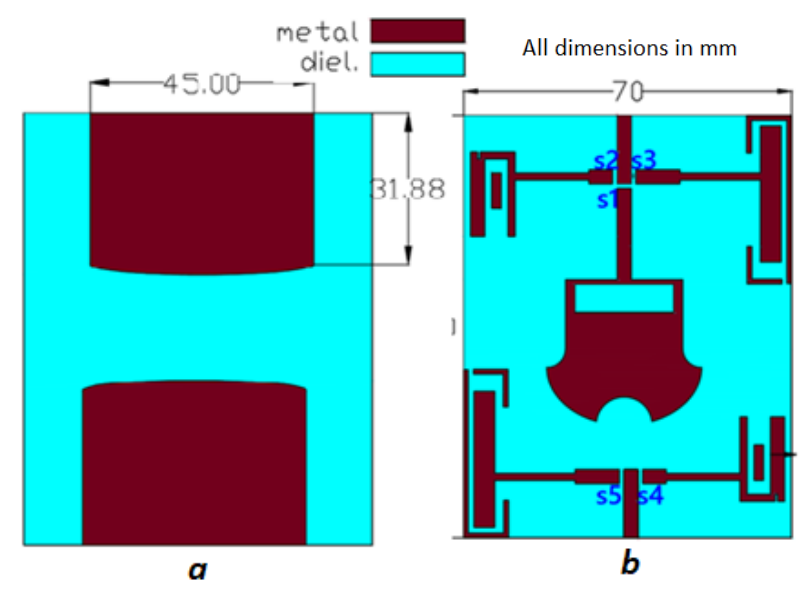

Figure 1. Geometry of the proposed antenna system;

(a) Front view, (b) Rear view

\subsection{Antenna-1}

The proposed cognitive radio antenna is constructed from three sections. In this antenna, the mid feed line is branched to three sub-lines each feeding a patch dedicated for a specific purpose. The central section is responsible of sensing while the lateral sections are used for communication.

\subsubsection{Sensing Section}

The central part of Antenna-1 which is a modified rectangular patch is used to sense the WB (2.2-4.5 GHz). This patch shown in Fig. 2-a is linked to the mid-feedline of the first antenna. Patch dimensions are basically computed according to the following equations [19]:

$$
\begin{aligned}
& W=\frac{c}{2 f_{r} \sqrt{\frac{2}{\varepsilon_{r}+1}}} \\
& L=L_{e f f}-2 \Delta L \\
& L_{\text {eff }}=\frac{c}{2 f_{r} \sqrt{\varepsilon_{\text {reff }}}} \\
& \Delta L=0, .412 h \frac{\left(\varepsilon_{r}+0.3\right)\left(\frac{W}{h}+0.264\right)}{\left(\varepsilon_{r}+0.258\right)\left(\frac{W}{h}+0.8\right)} \\
& \varepsilon_{\text {rreff }}=\frac{\varepsilon_{r}+1}{2}+\frac{\varepsilon_{r}-1}{2} \sqrt{12 \frac{W}{h}+1}
\end{aligned}
$$

Where;

$W$ : patch width, L:patch length, $f r$ : resonance frequency, $L_{e f f}$ : effective patch length,

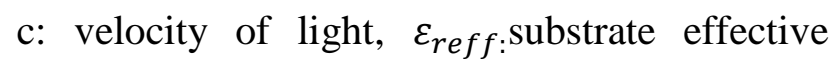
dielectric constant, $\varepsilon_{r}$ : substrate dielectric constant and $\Delta L$ : patch length extension.

To achieve targeted bandwidth, increase gain, reduce return loss and improve feedline matching; many modifications are introduced. These include a rectangular slot inside the main patch, a half-elliptical hat with half circular-slot, rounded corners and a shifting feed position. All these modifications, combined with partial ground, are optimized by a lot of simulations where parametric changes, including dimensions and positions, are carried out in order to obtain the appropriate design results.

\subsubsection{Communication Section}

As it was mentioned earlier, the first antenna has two sections dedicated for communication into two modes. The left section of Antenna-1 shown in Fig. 2-b is a $\mathrm{C}$ shape patch with a central bar designed to transmit in dual-band mode for WiFi/ C-band applications at (2.28-2.46 $\mathrm{GHz}) /(3.85-4.2 \mathrm{GHz})$ bands. While, the right section illustrated in Figure-2-c is a T- patch surrounded by two stubs of L and Gama $(\Gamma)$ shapes. This section works in the WiMax band (3.2-3.72 GHz). 
In the rear plane both patches have partial ground as shown in Fig. 1-b. These sections are built basically upon equations (1-5). Again, it should be mentioned that parametric values, shapes and locations of these structures are well studied in a lot of simulations till getting to the final design.

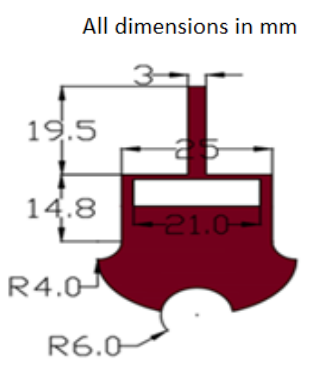

(a)

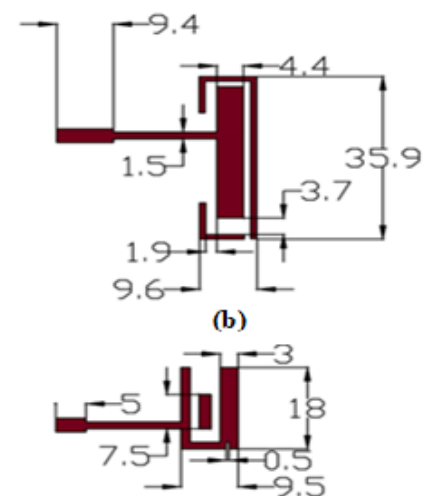

(c)
Figure 2. G Geometry of the three sections of Antenna-1

(a) Sensing Section, (b) Single-band comm. section, (c) Dual-band comm. section.

\subsection{Antenna-2}

The second antenna, which helps to obtain the benefits of MIMO, is constructed as an inverted clone of the communication sections of the Antenna-1 as shown in Fig. 1. The location of the antenna is carefully decided that miniaturizing the overall design and does not come on a mutual coupling penalty.

\subsection{Switches and Operation modes}

PIN switches located at the sub feed crossing point enable or disable various sections of the proposed system. The PIN diode is used to avoid high RF voltages on low distortion toggles and is especially suited for frequencies up to $3 \mathrm{GHz}$ [20]. Figure-3- shows the corresponding PIN diode circuit used in this design, the ON state PIN diode is modeled as $2.1 \mathrm{~K} \Omega$ resistor, and a parallel configuration of resistance $3 \mathrm{~K} \Omega$ and capacitance $0.17 \mathrm{pF}$ is modeled on the OFF state. All operation states of this design are illustrated in Table 1.

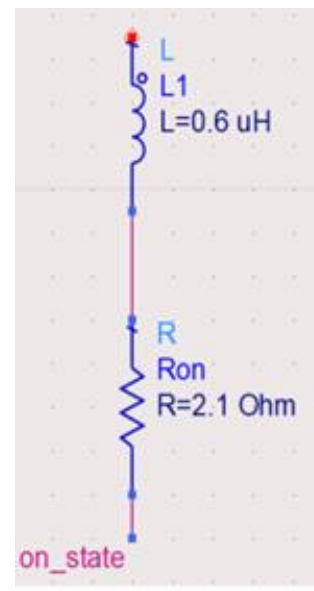

(a)

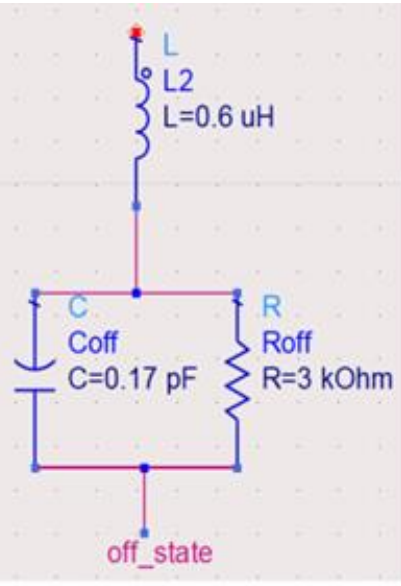

(b)
Figure 3. PIN diode equivalent circuits; (a) ON state, (b) OFF state

Table 1.Operation modes of the proposed antenna

\begin{tabular}{|c|c|c|c|}
\hline Mode & $\begin{array}{c}\text { ON- } \\
\text { Switch }\end{array}$ & $\begin{array}{l}\text { Operation } \\
\text { band }\end{array}$ & Description \\
\hline 1 & $\mathrm{~S} 1$ & $\begin{array}{c}2.24-4.5 \\
\mathrm{GHz}\end{array}$ & Sensing WB \\
\hline 2 & S2 & $\begin{array}{c}2.28-2.46 \\
\mathrm{GHz}, 3.85- \\
4.2 \mathrm{GHz}\end{array}$ & $\begin{array}{c}\text { Communication } \\
\text { dual-band WLAN + } \\
\text { C-band }\end{array}$ \\
\hline 3 & S3 & $\begin{array}{c}3.2-3.72 \\
\mathrm{GHz}\end{array}$ & $\begin{array}{c}\text { Communication } \\
\text { single-band WiMax }\end{array}$ \\
\hline 4 & $\mathrm{~S} 2+\mathrm{S} 4$ & $\begin{array}{c}2.28-2.46 \\
\mathrm{GHz}, 3.85- \\
4.2 \mathrm{GHz}\end{array}$ & $\begin{array}{c}\text { MIMO } \\
\text { Communication } \\
\text { dual-band } \\
\text { WLAN+C-band }\end{array}$ \\
\hline 5 & $\mathrm{~S} 3+\mathrm{S} 5$ & $\begin{array}{c}3.2-3.72 \\
\mathrm{GHz}\end{array}$ & $\begin{array}{c}\text { MIMO } \\
\text { Communication } \\
\text { single-band WiMax }\end{array}$ \\
\hline
\end{tabular}

\section{Results}

Antenna's performance and functionality are generally calculated according to several characteristics. Outcomes related to some of the most important of those characteristics are 
presented in this section. Those include input reflection coefficient, mutual coupling, realized gain, matching impedance, far field patterns, correlation and diversity.

\subsection{Input Reflection Coefficient (S11)}

Less power reflected to the antenna due to termination mismatch $\mathrm{S} 11$ is the basic parameter to decide antenna performance and operation. $\mathrm{S} 11$ below $-10 \mathrm{~dB}$ is usually required for judging the frequency region of operation. S11 results of the proposed antenna into its different modes are shown in Fig. 4. In the sensing mode; S11 crosses down the margin of $-10 \mathrm{~dB}$ within a WB of (2.24-4.5 GHz). Moreover S11 of $-43,-55$ and $-25 \mathrm{~dB}$ values are obtained at 3.16, 3.9 and 4.21 $\mathrm{GHz}$ respectively which are the resonant frequencies of this $2.26 \mathrm{GHz}$ band. In communication modes; it can be seen from the curves of Fig. 4 that in the single band mode, the low impedance bandwidth $(3.2-3.72 \mathrm{GHz})$ is obtained with a reflection coefficient value $36 \mathrm{~dB}$ at a resonant frequency of $3.39 \mathrm{GHz}$. On the other hand, the curve of $\mathrm{S} 11$ is below the -10 $\mathrm{dB}$ line within the $(2.28-2.46 \mathrm{GHz})$ and $(3.85-$ $4.2 \mathrm{GHz}$ ) bands of the dual-band communication mode. At resonance, it can be seen that $-23 \mathrm{~dB}$ and $-28 \mathrm{~dB}$ S11 values are obtained at $2.38 \mathrm{GHz}$ and $4 \mathrm{GHz}$ respectively.

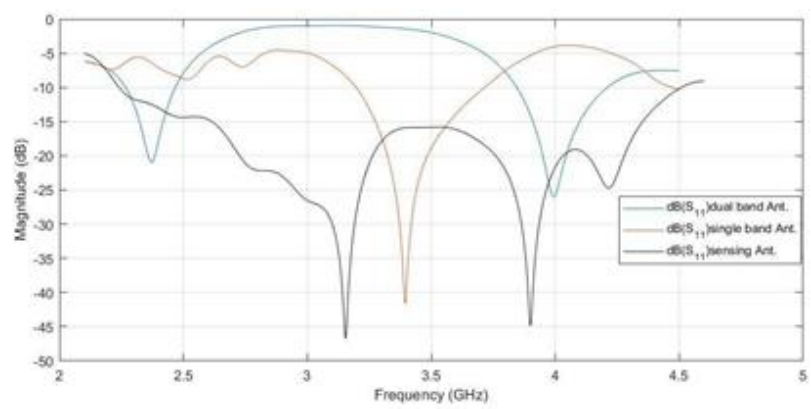

Figure 4. S11 at different operation modes

\subsection{Mutual Coupling}

The In the proposed design, a dual port antenna system is presented. Both antennas (Antenna-1 and Antenna-2) that are excited by different ports are operating in the MIMO communication modes (modes 4 and 5 in the table). In those modes it is very important to have as less as interoperation effect between the two antennas. S12 curves shown in Fig. 5 for both MIMO modes are acceptable which are below the $-10 \mathrm{~dB}$ line for all communication bands. It can also be seen that those values are $-17 \mathrm{~dB}$,$38 \mathrm{~dB}$ at resonance frequencies in the dual-band MIMO mode while it is $-23 \mathrm{~dB}$ for the singleband MIMO mode at resonance.

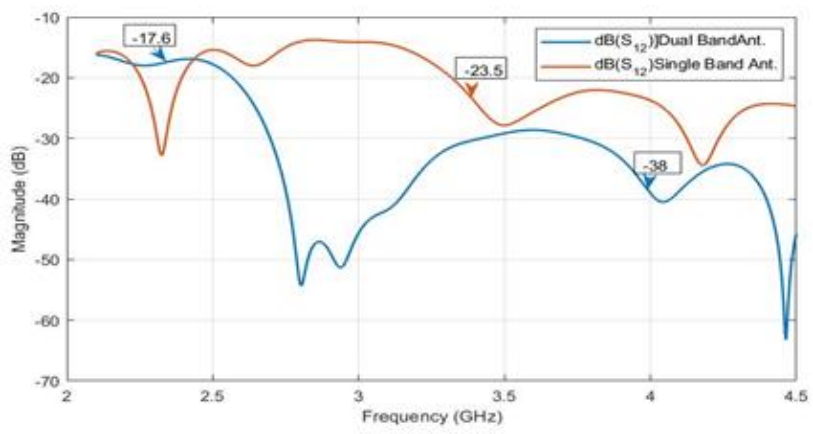

Figure 5. Mutual coupling at MIMO communication modes

\subsection{Realized Gain}

The realized gains in $\mathrm{dBi}$ for various modes of the proposed antenna against frequency are shown in Fig. 6. In the sensing mode a piecewise gain around $4 \mathrm{dBi}$ is obtained over the (2.24-4.5 $\mathrm{GHz}$ ) band. A satisfactory gain above $3 \mathrm{dBi}$ is obtained in the single-band communication mode with a peak value above $3 \mathrm{dBi}$ at the resonance frequency. Positive moderate gains over the sub bands of dual-band modes are obtained with approximately constant values that are greater than $2 \mathrm{dBi}$ and $3.5 \mathrm{dBi}$ for the WLAN and C-band respectively 


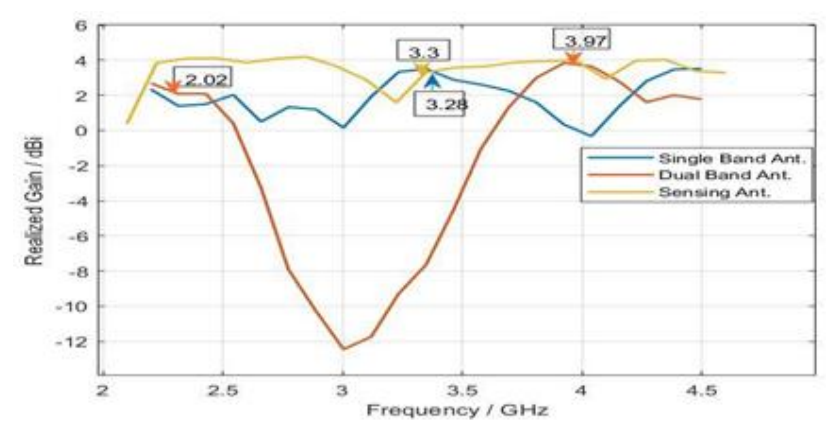

Figure 6. Realized gain at different operation modes

\subsection{Matching Impedance}

The simulated impedance matching for singleband, dual-band, and sensing modes of Antenna1 are shown in Fig. 7. As shown, the value of impedance matching of the proposed design approximate to $50 \Omega$ for all modes. Adjusting the antenna input impedance to $50 \Omega$ is so important for transferring the maximum power from the radio frequency circuits to the antenna without energy reflection.

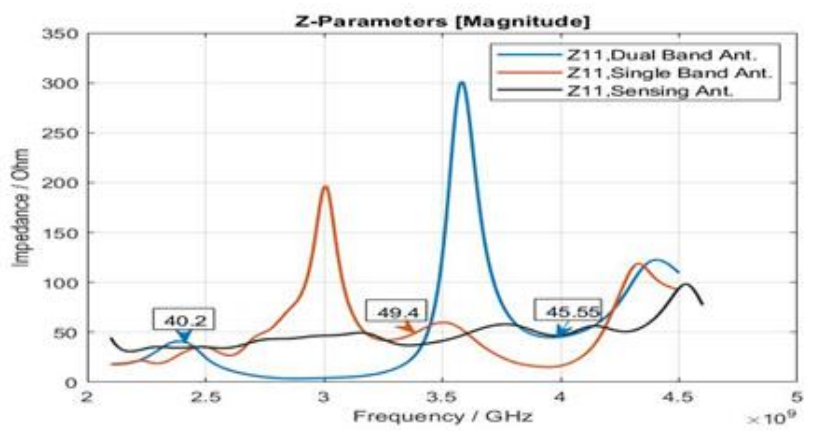

Figure 7. Impedance at different operation modes

\subsection{Radiation Patterns}

Radiation patterns at resonant frequencies for different operation modes of the proposed antenna are discussed in this paragraph. As illustrated in Fig. 8, the antenna in the simulation is laid in the $x-y$ plane where the feed of the central section extends along the $\mathrm{x}$-axis and for communication section it is along the y-axis. Fig. 9 shows an approximate omnidirectional pattern in the $y-z\left(\varphi=90^{\circ}\right)$ plane and bidirectional in the $\mathrm{x}-\mathrm{y}$ plane $\left(\theta=90^{\circ}\right)$ plane. Such patterns are usually desirable for cognitive radio applications. On the other hand; more directive patterns are seen in the E-plane (x-y plane) and H-plane ( $\mathrm{x}-\mathrm{z}$ plane) results of the communication modes at resonance frequencies as shown in Fig. 10.

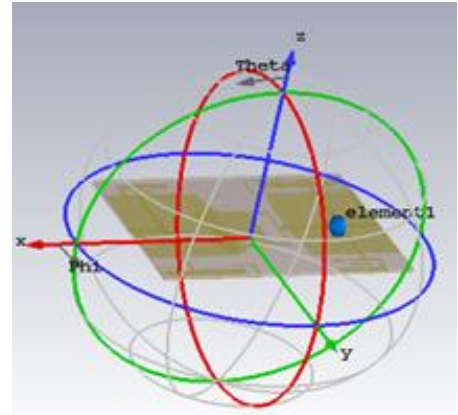

Figure 8. Orientation of the simulated proposed antenna

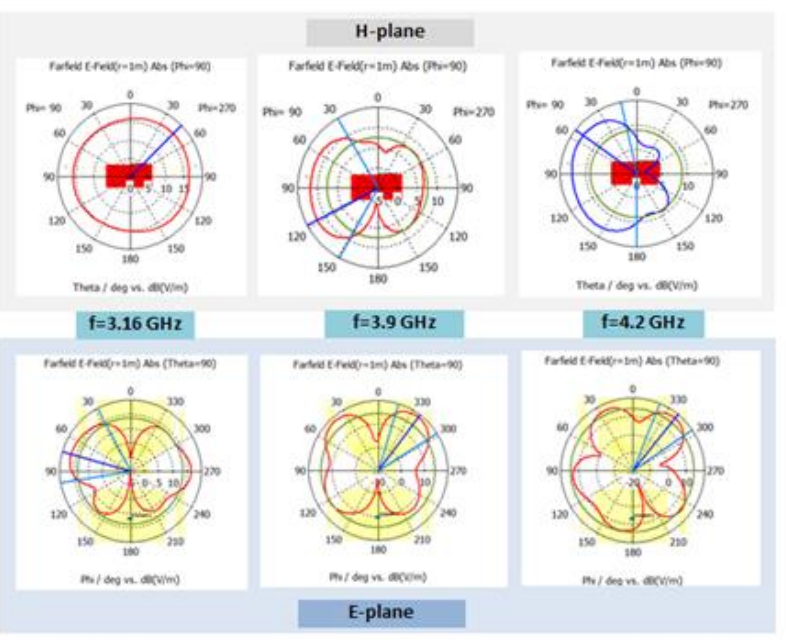

Figure 9. Radiation patterns of the proposed antenna system at sensing mode

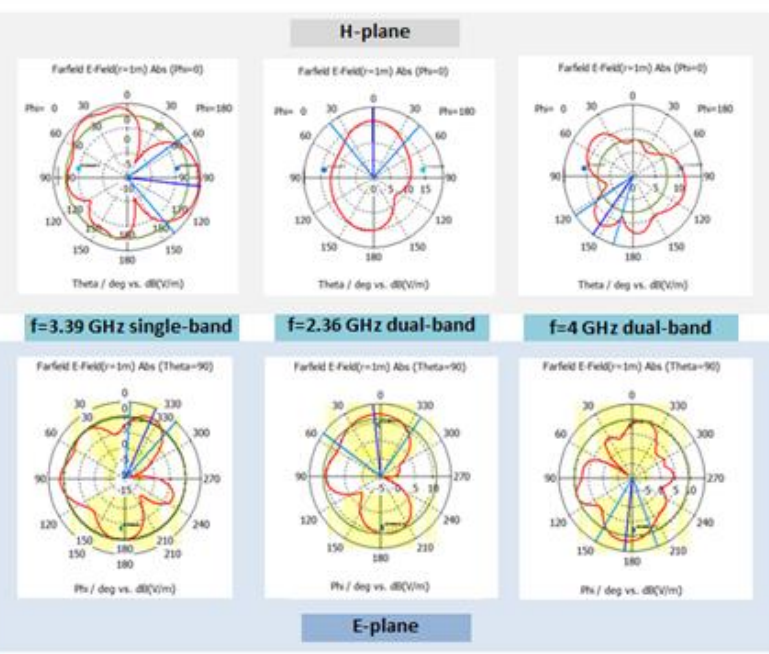

Figure 10. Radiation patterns of the proposed antenna at communication modes 


\subsection{Correlation and Diversity performance}

The efficiency of the MIMO antenna system is evaluated in this section in terms of the envelope correlation coefficient (ECC) and diversity gain (DG), where low ECC values determines the high isolation between the radiators. In general, the ECC value should be less than 0.5 and DG greater than 8.66 in order to achieve a good diversity characteristic for mobile terminal applications. These two important parameters may be calculated using (6) and (7), respectively $[21,22]$.

$$
\begin{aligned}
& \rho_{e}=\frac{\left|S_{i i}^{*} S_{i j}+S_{j i}^{*} S_{j j}\right|^{2}}{\left(1-\left|S_{i i}\right|^{2}-\left|S_{j i}\right|^{2}\right)\left(1-\left|S_{j j}\right|^{2}-\left|S_{i j}\right|^{2}\right)} \\
& D G=10 * \sqrt{1-\left|\rho_{e}\right|^{2}}
\end{aligned}
$$

Where,

$S_{i j:}$ is the coupling factor between $i^{t h}$ and $j^{\text {th }}$ elements and $\rho_{e}$ : is the envelope correlation coefficient.

Fig. 11 shows simulated ECC and DG in the whole operating unit, the ECC value is rather lower than 0.01. Since the ECC is very small, the elements of the MIMO antenna are less coupled and are well separated so the proposed MIMO antenna performance is excellent. As seen in the figure, DG's value is very close to 10 , ranging from 9.7 to 10 as the coefficient of envelope correlation values is very small.

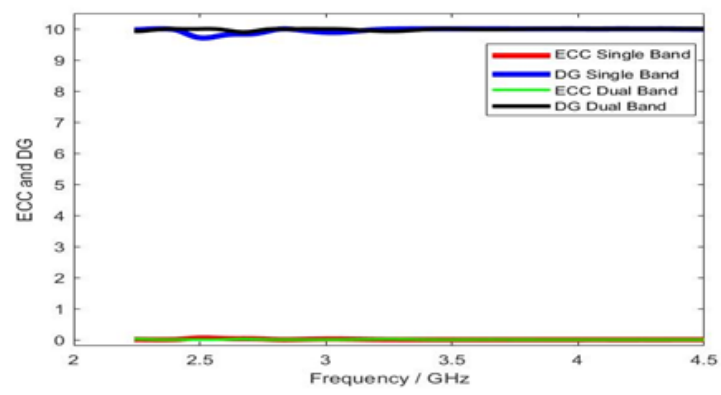

Figure 11. ECC and DG of the proposed antenna system at MIMO communication mods

\section{Comparison with previous designs}

The proposed system is compared to a number of previous works where comparison focusses the topics related to compactness, isolation, gain and complexity. A design that is relatively compact as compared to those in Table 2 with simple switching mechanism is presented. Five modes of operation including sensing a wide band is provided in this design which is an essential demand for interweave cognitive radio whereas most of the previous systems are only reconfigurable in specific bands. As a MIMO system isolation and ECC values are so important to support feasibility, the point which is clear from the good results related to these two factors as compared to previous designs. The proposed design also exhibits good results with respect to peak gain at resonance as compared to most of surveyed works.

\section{Conclusion}

The A dual-port antenna system is proposed which combines the characteristics of both cognitive radio and MIMO diversity. The results of the reflection coefficient show that, in all modes, frequency reconfigurable characteristics at resonance frequencies are a good proof of the feasibility of operation within targeted bands and well matched to the feed. The effects of mutual coupling also show strong isolation between the two antennas. Positive and satisfactory piecewise constant gains are obtained over the operating bands which is desired in cognitive radio antenna systems. Resultant far-field patterns that are omnidirectional for sensing and directive for communication are desirable. ECC values approach 0 and DG values that approach 10 insures good MIMO characteristics. Therefore, the proposed system depending on the obtained results looks suitable for existing wireless technologies of communication. 
Table 2. Comparison with surveyed designs

\begin{tabular}{|c|c|c|c|c|c|c|c|c|}
\hline Ref. & Size $(\mathrm{mm} 3)$ & $\begin{array}{c}\text { Op. Bands } \\
\text { (GHz) }\end{array}$ & $\begin{array}{c}\text { WB } \\
\text { sensing }\end{array}$ & Isolation & $\begin{array}{l}\text { Switch. } \\
\text { Tech }\end{array}$ & $\mathrm{ECC}$ & $\begin{array}{l}\text { Peak Gain } \\
\text { (dBi) }\end{array}$ & $\begin{array}{l}\text { No. of } \\
\text { Elem. }\end{array}$ \\
\hline [12] & $\begin{array}{c}120 \times 65 \\
\times 1.56\end{array}$ & $\begin{array}{c}0.58-0.68 \\
0.834-1.12\end{array}$ & $\begin{array}{c}\sqrt{ } \\
(0.72- \\
3.44)\end{array}$ & $>11 \mathrm{~dB}$ & $\begin{array}{c}\text { PIN diodes, } \\
\text { Varactor } \\
\text { diodes }\end{array}$ & $<0.06$ & $1-2.92$ & 2 \\
\hline [13] & $\begin{array}{c}150 \times 150 \\
\times 3.17\end{array}$ & $\begin{array}{l}1.68-1.93 \\
2.11-2.51\end{array}$ & $\mathrm{x}$ & N/A & $\begin{array}{c}\text { Varactor } \\
\text { diodes }\end{array}$ & N/A & $\begin{array}{c}4-8 \\
\text { Unidir. }\end{array}$ & 2 \\
\hline [14] & $\begin{array}{c}100 \times 50 \\
\times 0.8\end{array}$ & $2.12-2.32$ & $\mathrm{x}$ & $>12 \mathrm{~dB}$ & $\begin{array}{l}\text { Varactor } \\
\text { diodes }\end{array}$ & $<0.11$ & $2.5-2.67$ & 2 \\
\hline [15] & $\begin{array}{c}120 \times 60 \\
\times 0.76\end{array}$ & $1.8-2.45$ & $\mathrm{x}$ & $>10 \mathrm{~dB}$ & $\begin{array}{c}\text { Varactor } \\
\text { diodes }\end{array}$ & $<0.186$ & $-2.6-2.43$ & 4 \\
\hline [16] & $\begin{array}{c}120 \times 60 \\
\times 1.56\end{array}$ & $3.2-3.9$ & $\mathrm{x}$ & $>9 \mathrm{~dB}$ & $\begin{array}{c}\text { Varactor } \\
\text { diodes }\end{array}$ & $<0.25$ & $2.2-4.5$ & 4 \\
\hline [17] & $\begin{array}{c}120 \times 60 \\
\times 1.6\end{array}$ & $1.3-2.6$ & $\mathrm{x}$ & $>12 \mathrm{~dB}$ & $\begin{array}{c}\text { Varactor } \\
\text { diodes }\end{array}$ & $<0.2$ & $-1.9-2.48$ & 4 \\
\hline [18] & $\begin{array}{c}145 \times 72 \\
x 0.8\end{array}$ & $\begin{array}{l}0.88-.96 \\
1.64-2.18 \\
2.15-2.78\end{array}$ & $\mathrm{x}$ & $>17 \mathrm{~dB}$ & PIN diodes & $<0.35$ & $1.6-4.8$ & 2 \\
\hline Prop. & $\begin{array}{c}90 \times 70 \\
\times 1.6\end{array}$ & $\begin{array}{l}2.28-2.46 \\
3.2-3.72 \\
3.85-4.2\end{array}$ & $\begin{array}{c}\sqrt{ } \\
(2.24-4.5)\end{array}$ & $>17 \mathrm{~dB}$ & PIN diodes & $<0.001$ & $2.02-3.97$ & 4 \\
\hline
\end{tabular}

\section{Acknowledgements}

The authors would like to thank Mustansiriyah University (www.uomustansiriyha.edu.iq) Baghdad, Iraq for its support in the present work.

\section{Conflict of interest}

The authors declares that there is no conflict of interest.

\section{References}

[1] Trump, T. (2017). "Cognitive Radio", InTech.

[2] Tawk, Y., J. Costantine, and C. Christodoulou (2016). "Antenna Design for Cognitive Radio”, Artech House.

[3] Al-Muttairi, A. I. and M. J. Farhan (2020). "Frequency reconfigurable monopole antenna 
with harmonic suppression for IoT applications", TELKOMNIKA Telecommunication,

Computing, Electronics and Control, Vol. 18, pp. 10-18.

[4] Devi, G. A., J. Aarthi, P. Bhargav, R. Pandeeswari, M. A. Reddy, and R. S. Daniel (2017). "UWB frequency reconfigurable patch antenna for cognitive radio applications IEEE”, 2017 IEEE International Conference on Antenna Innovations \& Modern Technologies for Ground, Aircraft and Satellite Applications (iAIM), pp. 14.

[5] Koley, S., B. Dipen, and M. Debjani (2015). "Band-Reconfigurable Monopole Antenna for Cognitive Radio Applications”, IETE Journal of Research, Vol. 61, pp. 1-6.

[6] Mansoul, A., F. Ghanem, H. M. Rijal, T. Mohamed (2014). "A Selective FrequencyReconfigurable Antenna for Cognitive Radio Applications", IEEE Antennas and Wireless Propagation Letters, Vol. 13, pp. 515-518.

[7] Ge, L. and K.-M. Luk (2014). "Frequencyreconfigurable low-profile circular monopolar patch antenna", IEEE Transactions on Antennas and Propagation, Vol. 62, pp. 3443-3449.

[8] Nemati, N. and M. Bemani (2019). "A novel reconfigurable microstrip fractal UWB antenna with six variable rejection frequency bands", International Journal of Microwave and Wireless Technologies, Vol. 12, pp. 148-154.

[9] Okazeri, K., K. Muraoka, Y. Shoji, S. Nakagawa, N. Nishiyama, S. Arai, and T. Mizumoto (2018). "Self-holding magnetooptical switch integrated with thin-film magnet", IEEE Photonics Technology Letters, Vol. 30, pp. 371-374.

[10] Sheikh, M. U., R. Jagusz, and J. Lempiäinen (2011). "Performance evaluation of Adaptive MIMO Switching in Long Term Evolution", 2011 7th International Wireless Communications and Mobile Computing Conference, pp. 866-870.
[11] Yu, X. , L. Wang, H.-G. Wang, X. Wu, and Y.-H. Shang (2012). "A novel multiport matching method for maximum capacity of an indoor MIMO system", Progress In Electromagnetics Research, Vol. 130, pp. 67-84.

[12] Hussain, R. and M. S. Sharawi (2015). "A Cognitive Radio Reconfigurable MIMO and Sensing Antenna System", IEEE Antennas and Wireless Propagation Letters, Vol. 14, pp. 257260.

[13] Ge L, Li M, Wang J and Gu H. (2017). "Unidirectional dual-band stacked patch antenna with independent frequency", IEEE Antennas Wireless Propagation Letters, Vol.16, pp. 113-116.

[14] Raza A., Khan MU. and Tahir FA. (2017). "A frequency reconfigurable MIMO antenna system for cognitive radio applications", Frequenz.

[15] Hussain R., Ghalib A, Sharawi MS. (2017). "Annular slot-based miniaturized frequencyagile MIMO antenna system". IEEE Antennas and Wireless Propagation Letters, Vol.16, pp. 2489-2492.

[16] Hussain R., Ali Raza, Muhammad U. Khan , Atif Shammim, and Mohammad S. Sharawi (2019). "Miniaturized frequency reconfigurable pentagonal MIMO slot antenna for interweave $C R$ applications", Internaltional journal of RF and microwave computer-aided engineering.

[17] Zhao X and Riaz S. (2018). "A dual-band frequency reconfigurable MIMO patch-slot antenna based on reconfigurable microstrip feedline", IEEE Access, Vol.6, pp. 41450-41457.

[18] Xu Z., Sun YT, Zhou QQ, Ban YL, Li YX and Ang SS. (2017). "Reconfigurable MIMO antenna for integrated-metal-rimmed smartphone applications". IEEE Access, Vol.5, pp. 21223-212289. 
[19] Balanis, C. A. (2016). “Antenna Theory: Analysis and Design", John Wiley \& Sons.

[20] BAR64-05, Infineon Technologies AG 81726 Munich, Germany, 2018.

[21] Lee, J. -H. and C.-C. Cheng (2012). "Spatial correlation of multiple antenna arrays in wireless communication systems", Progress In Electromagnetics Research, Vol. 132, pp. 347368 .

[22] Kharche, S. U., G. S. Reddy, B. Mukherjee, R. K. Gupta, and J. Mukherjee (2014). "MIMO antenna for Bluetooth, Wi-Fi, Wi-Max and UWB applications", Progress In Electromagnetics Research C, Vol. 52, pp. 53-62. 